\title{
Fabrication Polyvinyl alcohol - Poly-Acrylic acid/ Niobium Carbide New Bio-Films for Antibacterial Applications
}

\author{
Ahmed Hashim* and Zinah Sattar Hamad \\ University of Babylon, College of Education for Pure Sciences, Department of Physics, Iraq \\ [?] \\ Correspondence Author: Ahmed Hashim. University of Babylon, College of Education for Pure Sciences, Department of Physics, Iraq \\ E-mail: ahmed_taay@yahoo.com
}

Received date: 19 May 2018, Accepted date: 15 August 2018, Online, Online date: 20 August 2018

Copyright: (C) 2018 Ahmed Hashim and Zinah Sattar Hamad., This is an open-access article distributed under the terms of the Creative Commons Attribution License, which permits unrestricted use, distribution, and reproduction in any medium, provided the original auth or and source are credited.

\begin{abstract}
Films of polyvinyl alcohol - poly-acrylic acid biopolymer blend and biopolymer blend doped with niobium carbide nanoparticles have been prepared by using casting method for antibacterial application. Bionanocomposites were prepared with concentration polyvinyl alcohol (85 wt.\%) and poly-acrylic acid (15 wt.\%). The niobium carbide nanoparticles were added to biopolymer blend by different concentrations. The (PVA-PAA-NbC) nanocomposites were tested for antibacterial against staphylococcus aureus (S. aureus). The experimental results showed that the nanocomposites have good activity for antibacterial.
\end{abstract}

Key words: nanocomposites, antibacterial, staphylococcus aureus, biopolymer

\section{INTRODUCTION}

Nowadays, microbial infections are a great concern because they are one of the main primary causes of death worldwide, especially in healthcare institutions, where people are generally more vulnerable. This fact is mainly due to the persistence of potentially pathogenic microbes (bacteria, viruses and fungi) in several locations, such as textiles, healthcare products, medical devices, water purification systems, sanitation facilities, among others. Particular relevance is given to the medical field, in which healthcare infections represent the majority of the adverse events occurring in hospitals. Moreover, most patients exposed to the microorganisms are already in poor health conditions and, therefore, are unable to resist further disorders and other additional complications. For instance, serious infections derived from the use of long-term medical implants (e.g., catheters) can be caused by bacteria that are resistant to different antibiotics. Indeed, the increasing growth of multidrug-resistant microbes, along with the fact that they can easily spread to different environments and by different ways (air, soil and water), makes the prevention of antimicrobial infections very challenging [1]. Gradual development of different antibiotic resistant bacterial strains has nowadays made it imperative to research new drugs or materials with a wide spectrum of effective antimicrobial activities. Recent studies on nanomaterials elicit that different metallic and metal oxide nanoparticles (NPs) may have very promising and potent roles as antimicrobial agents. Such NPs, due to their large surface to volume ratio and crystalline structure, trigger biological responses different from those produced by the traditional ionic form of the metals. Moreover, metallic NPs were found to have (a) 7-50 times less toxic effect to mammalian cells than their corresponding ionic forms and (b) prolonged effect as a source of elements in an organism [2]. Polyvinyl alcohol (PVA) is an important water-soluble transparent polymer and is extensively used in industries due to the excellent chemical and physical properties, non-toxicity, good chemical resistance, good film formation capacity, biodegradability and high crystal modulus. PVA is used here in hydrolyzed form with the degree of $85 \%$ hydrolysis. It is a polymer with many technological, pharmaceutical and biomedical applications [3]. Poly (vinyl alcohol) (PVA) is a biodegradable synthetic polymer, which is a kind of thin film material with excellent performance and wide application. In addition, the research results on the composite film of polyvinyl alcohol (PVA) with a variety of materials, including essential oils, modified nanomaterials etc., proved its good packaging performance, and the existence of film pores and the size of the loading affect the number of antimicrobial agents, thus affecting the antibacterial properties of the film [4]. The metal nanoparticles exhibit unique optical, electrical, magnetic, thermal, chemical and biological properties, providing opportunities for potential technological, biological, medical applications [5]. Nanocomposites materials have properties combine the properties of the filler and matrix. The new material has applications in fields: antibacterial [6-11], humidity sensors [12-17], pressure sensors and piezoelectric [18-22], radiation shielding [23-25] and thermal energy storage and release [26-29]. Niobium carbide is type of transition metals carbides which has unique properties resembling with metal and ceramic constituents and used in many technological applications due to their high strength, durability [30].

\section{MATERIALS AND METHODS}

The nanocomposites of polyvinyl alcohol (PVA)- poly-acrylic acid (PAA) and polyvinyl alcohol- poly-acrylic acid doped with niobium carbide (NbC) nanoparticles have been prepared by using casting method. The (PVA-PAA-NbC) nanocomposites films were prepared by dissolving $1 \mathrm{gm}$ of polymers with concentration $85 \mathrm{wt} . \%$ PVA and $15 \mathrm{wt} . \%$ PAA by using magnetic stirrer to mix the blend for 1 hour to obtain more homogeneous solution. The NbC nanoparticles were added to blend with concentrations are $(1.5,3,4.5$ and 6$) \mathrm{wt} . \%$. Antibacterial activity of the nanocomposites tested samples was determined using a disc diffusion method. The antibacterial activities were done by using gram positive organisms (Staphylococcus aureus). The disks of nanocomposites were placed over the media and incubated at $37^{\circ} \mathrm{C}$ for 24 hours. The inhibition zone diameter was measured. 


\section{Characteristics Breeders:}

The arrangements of $\mathrm{NbC}$ nanoparticles in (PVA-PAA) blend at magnification power (40x) is shown in figure 1. The figure shows that the $\mathrm{NbC}$ nanoparticles is aggregated as a cluster at lower concentrations. When increasing the concentrations of $\mathrm{NbC}$ nanoparticles, the nanoparticles form a paths network inside the (PVA-PAA) blend [31]. This behavior consistent with the results of researchers [32,33].

The antibacterial properties of the (PVA-PAA-NbC) nanocomposites were tested against gram-positive (Staphylococcus aureus) and the obtained data are presented in figure 2. From the figure, it can see the inhibition zone increases with increasing the concentrations of NbC nanoparticles. The toxic mechanisms of antimicrobial materials coming from the mixture of an antimicrobial agent and a non-active polymer, are as similar as the mechanism of the agent itself. In polymer/metal nanocomposites therefore the main toxic mechanism relates with the nanoparticles meaning, as previously discussed, two possible routes depending on the species considered as the active agent: (1) the metal nanoparticle or (2) the metal ions released from the particles. However, a growing number of reports indicate that the ion release is the driving force behind the antimicrobial properties of antibacterial nanoparticles. In fact, most of the analyses regarding antimicrobial metal nanoparticles focused on the metal ion release instead of the particle absorbed by the bacteria. This was confirmed by the results coming from polymer/metal nanocomposites where the antimicrobial effect of these materials related with the metal ion releases rather than with the leaching of the particle [34].
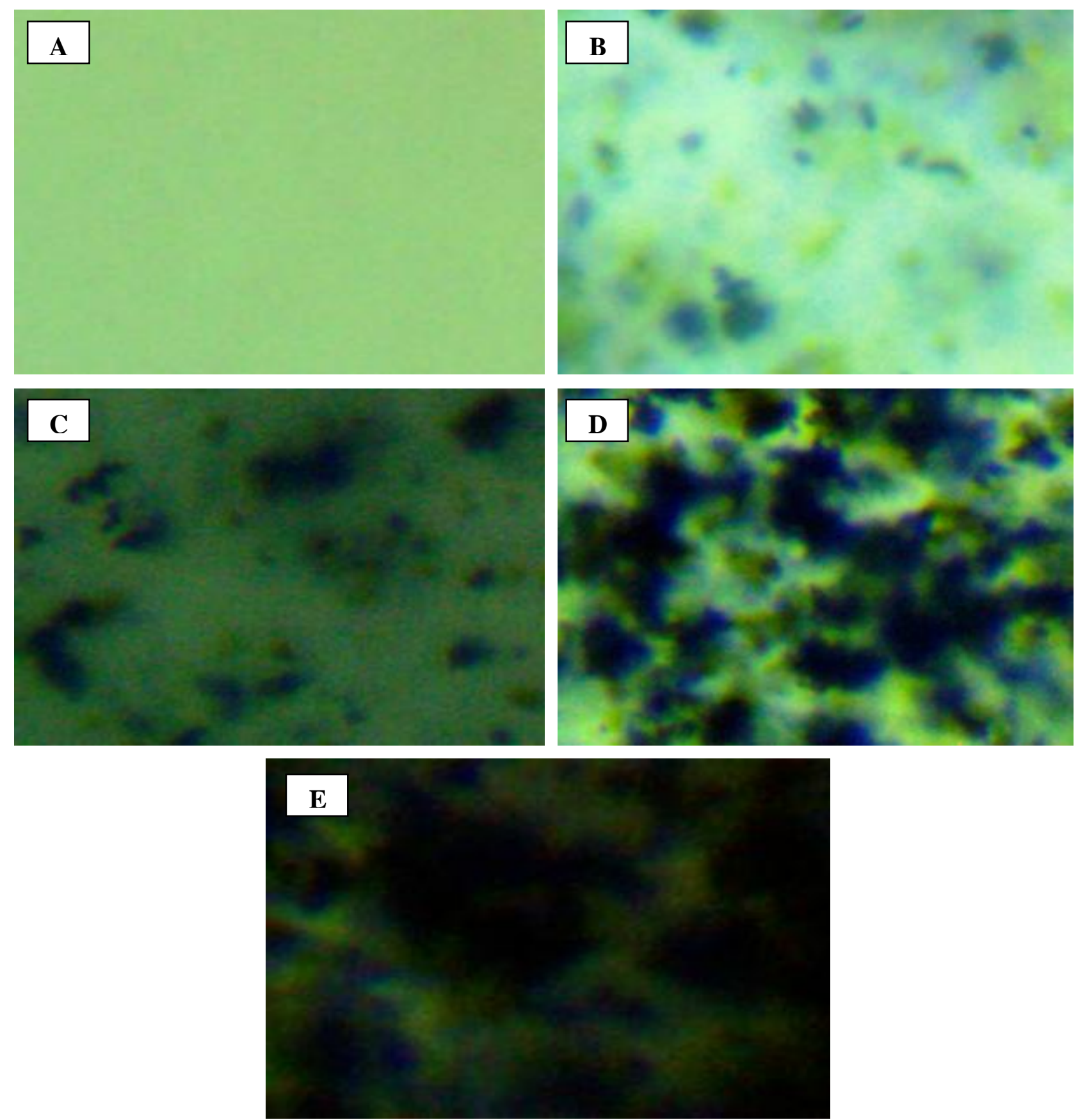

Fig. 1. Photomicrographs (40X) for (PVA-PAA-NbC) nanocomposites: (A) for (PVA-PAA) blend, (B) for $1.5 \mathrm{wt} . \% \mathrm{NbC},(\mathrm{C})$ for $3 \mathrm{wt} . \% \mathrm{NbC}$, (D) for $4.5 \mathrm{wt} \% \mathrm{NbC}$, (E) for $6 \mathrm{wt} . \% \mathrm{NbC}$. 


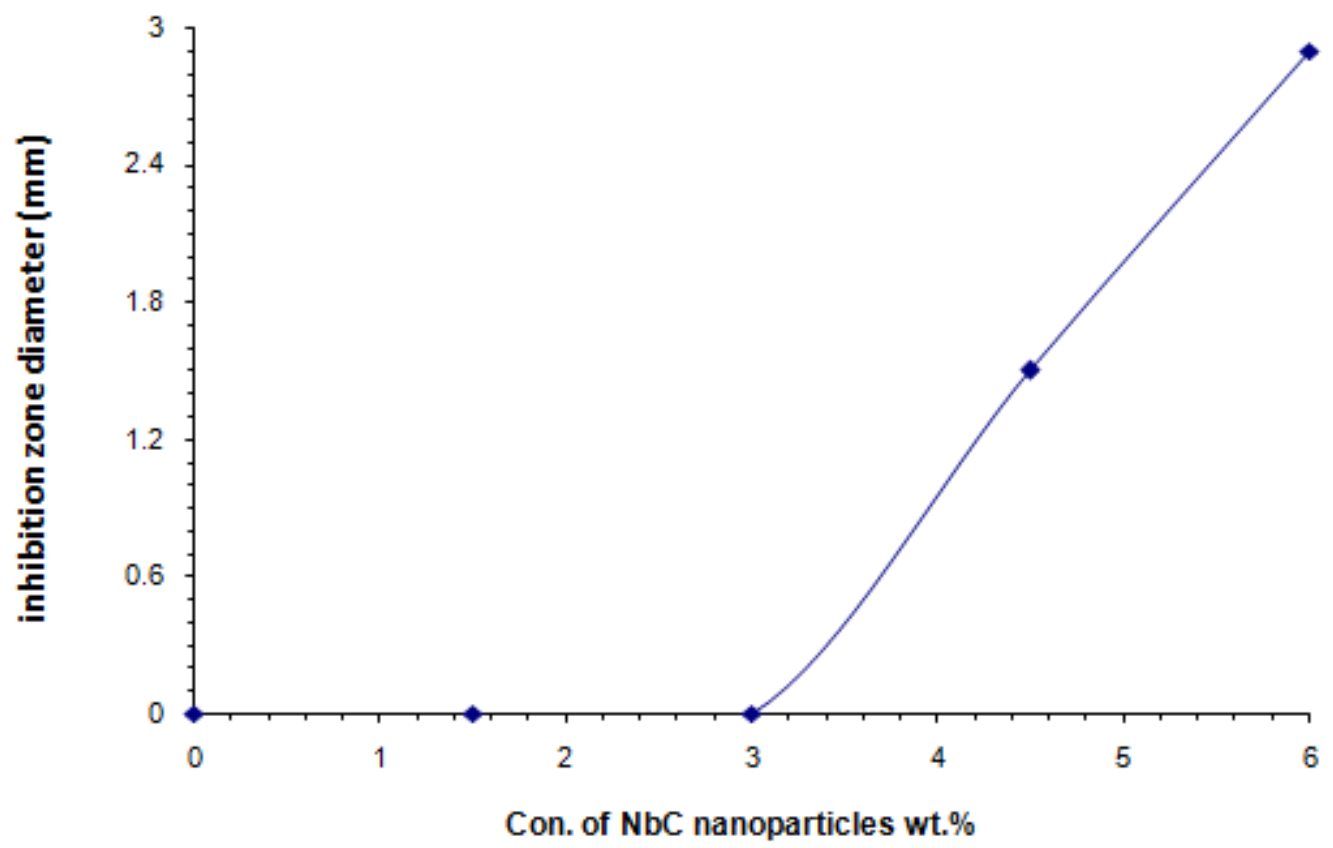

Fig. 2. Variation of inhibition zone diameter with concentration of $\mathrm{NbC}$ nanoparticles against gram-positive (Staphylococcus aureus).

\section{CONCLUSIONS}

1- The $\mathrm{NbC}$ nanoparticles is aggregated as a cluster at lower concentrations. At high concentrations of NbC nanoparticles, the nanoparticles form a paths network inside the (PVA-PAA) blend.

2- $\quad$ The inhibition zone for $\mathrm{S}$. aureus increases with increase in concentrations of $\mathrm{NbC}$ nanoparticles.

3- The (PVA-PAA-NbC) nanocomposites have good antibacterial activity against Staphylococcus aureus.

\section{REFERENCES}

[1] Madson R. E. Santos, Ana C. Fonseca, Patrícia V. Mendonça, Rita Branco, Arménio C. Serra, Paula V. Morais and Jorge F. J. Coelho, Recent Developments in Antimicrobial Polymers: A Review, Materials, Vol.9, No.599, (2016).

[2] Arijit Kumar Chatterjee, Ruchira Chakraborty and Tarakdas Basu, Mechanism of antibacterial activity of copper nanoparticles, Nanotechnology, Vol.25, (2014).

[3] Alireza Samzadeh-Kermani, Mohsen Mirzaee, Mansour Ghaffari-Moghaddam, Polyvinyl Alcohol/Polyaniline/ZnO Nanocomposite: Synthesis, Characterization and Bactericidal Property, Advances in Biological Chemistry, Vol.6, (2016).

[4] Zhijun Wu, Jinging Wu, Tingting Peng, Yutong Li, Derong Lin, Baoshan Xing, Chunxiao Li, Yuqiu Yang, Li Yang, Lihua Zhang, Rongchao Ma, Weixiong Wu, Xiaorong Lv, Jianwu Dai and Guoquan Han, Preparation and Application of Starch/Polyvinyl Alcohol/Citric Acid Ternary Blend Antimicrobial Functional Food Packaging Films, Polymers, Vol. 9, No.102, (2017).

[5] J. Meena Devi and M. Umadevi, Synthesis and Characterization of Silver-PVA Nanocomposite for Sensor and Antibacterial Applications, J Clust Sci., DOI 10.1007/s10876-013-0660-6.

[6] Farhan Lafta Rashid, Aseel Hadi, Naheda Humood Al-Garah, Ahmed Hashim, Novel Phase Change Materials, MgO Nanoparticles, and Water Based Nanofluids for Thermal Energy Storage and Biomedical Applications, International Journal of Pharmaceutical and Phytopharmacological Research, Vol.8, Issue 1, (2018).

[7] Naheda Humood Al-Garah, Farhan Lafta Rashid, Aseel Hadi, and Ahmed Hashim, Synthesis and Characterization of Novel (Organic-Inorganic) Nanofluids for Antibacterial, Antifungal and Heat Transfer Applications, Journal of Bionanoscience, Vol. 12, (2018).

[8] Ibrahim R. Agool, Kadhim J. Kadhim and Ahmed Hashim, Synthesis of (PVA- PEG-PVP-MgO) Nanobiomaterials and their Application, Advances in Environmental Biology, Vol.9, No.27, (2015).

[9] Kadhim J. Kadhim, Ibrahim R.Agool and Ahmed Hashim, Enhancement in Optical Properties of (PVA-PEG-PVP) Blend By the Addition of Titanium Oxide Nanoparticles For Biological Application, Advances in Environmental Biology, Vol.10, No.1, (2016).

[10] Kadhim J. Kadhim, Ibrahim R. Agool and Ahmed Hashim, Effect of Zirconium Oxide Nanoparticles on Dielectric Properties of (PVA-PEG-PVP) Blend for Medical Application, Journal of Advanced Physics, Vol.6, No.2, (2017).

[11] Kadhim J. Kadhim, Ibrahim R. Agool and Ahmed Hashim, Synthesis of (PVA-PEG-PVP-TiO2) Nanocomposites for Antibacterial Application, Materials Focus, Vol.5, No.5, (2016).

[12] I. R. Agool, K. J. Kadhim, A. Hashim, Fabrication of new nanocomposites: (PVA-PEG-PVP) blend-zirconium oxide nanoparticles) for humidity sensors, International Journal of Plastics Technology, Vol.21, Issue 2, (2017).

[13] A. Hadi, A. hashim, development of a new humidity sensor based on (carboxymethyl cellulose-starch) blend with copper oxide nanoparticles, Ukrainian Journal of Physics, Vol. 62, No. 12, (2017).

[14] A. Hashim and Q. Hadi, Structural, electrical and optical properties of (biopolymer blend/ titanium carbide) nanocomposites for low cost humidity sensors, Journal of Materials Science: Materials in Electronics,Vol.29, pp.11598-11604, (2018).

[15] A. Hashim and Q. Hadi, Synthesis of Novel (Polymer Blend-Ceramics) Nanocomposites: Structural, Optical and Electrical Properties for Humidity Sensors, Journal of Inorganic and Organometallic Polymers and Materials, Vol.28, Issue 4, pp 1394-1401, (2018). 
[16] Ahmed Hashim, Majeed Ali Habeeb, and Aseel Hadi, Synthesis of Novel Polyvinyl Alcohol-Starch-Copper Oxide Nanocomposites for Humidity Sensors Applications with Different Temperatures, Sensor Letters, Vol.15, No.9, PP.758-761, (2017).

[17] Ahmed Hashim and Aseel Hadi, Synthesis and Characterization of (MgO-Y2O3-CuO) Nanocomposites for Novel Humidity Sensor Application, Sensor Letters, Vol.15, (2017).

[18] Ahmed Hashim and Qassim Hadi, Novel of (Niobium Carbide/Polymer Blend) Nanocomposites: Fabrication and Characterization for Pressure Sensor, Sensor Letters, Vol.15, (2017).

[19] Ahmed Hashim, Majeed Ali Habeeb, Aseel Hadi, Qayssar M. Jebur, and Waled Hadi, Fabrication of Novel (PVA-PEG-CMC-Fe3O4) Magnetic Nanocomposites for Piezoelectric Applications, Sensor Letters, Vol.15, No.12, (2017).

[20] Ahmed Hashim, Majeed Ali Habeeb, Abdulameer Khalaf, Aseel Hadi, Synthesis of Novel (Polymer Blend-Titanium Carbide) Nanocomposites and Studying their Characterizations for Piezoelectric Applications, Journal of University of Babylon, Pure and Applied Sciences, Vol. 26, No. 6, (2018).

[21] Ahmed Hashim and Aseel Hadi, A Novel Piezoelectric Materials Prepared from (Carboxymethyl Cellulose-Starch) Blend-Metal Oxide Nanocomposites, Sensor Letters, Vol.15, No.12, (2017).

[22] Ahmed Hashim and Aseel Hadi, Novel Pressure Sensors Made From Nanocomposites (Biodegradable Polymers-Metal Oxide Nanoparticles): Fabrication And Characterization, Ukrainian Journal of Physics, Vol. 63, No. 8, (2018).

[23] Ahmed Hashim and Ali Jassim, Novel of Biodegradable Polymers-Inorganic Nanoparticles: Structural, Optical and Electrical Properties as Humidity Sensors and Gamma Radiation Shielding for Biological Applications, Journal of Bionanoscience, Vol. 12, (2018).

[23] A. Hashim and A. Hadi, novel lead oxide polymer nanocomposites for nuclear radiation shielding applications, Ukrainian Journal of Physics, Vol.62, No.11, (2017).

[24] Ahmed Hashim and Ali Jassim, Novel of (PVA-ST-PbO2) Bio Nanocomposites: Preparation and Properties for Humidity Sensors and Radiation Shielding Applications, Sensor Letters, Vol.15, No.12, (2017).

[25] M. A. Habeeb, A. Hashim, and A. Hadi, Fabrication of New Nanocomposites: CMC-PAA-PbO2 Nanoparticles for Piezoelectric Sensors and Gamma Radiation Shielding Applications, Sensor Letters, Vol.15, No.9, PP. 785-790, (2017).

[26] A. Hashim, I. R. Agool and K. J. Kadhim, Novel of (Polymer Blend-Fe3O4) Magnetic Nanocomposites: Preparation and Characterization For Thermal Energy Storage and Release, Gamma Ray Shielding, Antibacterial Activity and Humidity Sensors Applications, Journal of Materials Science: Materials in Electronics, Vol. 29, Issue 12, pp. 10369-10394, (2018).

[27] Ibrahim R. Agool, Kadhim J. Kadhim, Ahmed Hashim, Preparation of (polyvinyl alcohol-polyethylene glycol- polyvinyl pyrrolidinone-titanium oxide nanoparticles) nanocomposites: electrical properties for energy storage and release, International Journal of Plastics Technology, Vol.20, No. 1, PP. 121-127, (2016).

[28] Ibrahim R. Agool, Kadhim J. Kadhim, Ahmed Hashim, Synthesis of (PVA-PEG-PVP-ZrO2) Nanocomposites For Energy Release and Gamma Shielding Applications, International Journal of Plastics Technology, Vol.21, Issue 2, (2017).

[29] A. Hashim, A. Hadi, synthesis and characterization of novel piezoelectric and energy storage nanocomposites: biodegradable materials-magnesium oxide nanoparticles, Ukrainian Journal of Physics, Vol. 62, No.12, (2017).

[30] Ahmed Al-Ghaban, Kadhum Mutter Shabeeb, and Aseel Hadi Hamaza, Structural, Physical and Mechanical Properties of Novel TiC/NbC Nanoparticles, Journal of Advanced Physics Vol. 6, No.3, (2017).

[31] O. Abdullah, D. R. Saber and L. O. Hamasalih, Complexion Formation in PVA/PEO/CuCl2 Solid Polymer Electrolyte, Universal Journal of Materials Science, Vol. 3, No. 1, (2015).

[32] Elena Părpăriţăa, Cătălina N. Cheaburu, Silvia Florica Pațachia, Cornelia Vasile, Polyvinyl alcohol/chitosan/montmorillonite nanocomposites preparation by freeze/thaw cycles and characterization, ACTA CHEMICA IASI, Vol.22, (2014).

[33] Hassan M. Ibrahim, Enas M.R. El- Zairy, Carboxymethylchitosan nanofibers containing silver nanoparticles: Preparation, Characterization and Antibacterial activity, Journal of Applied Pharmaceutical Science Vol. 6, (2016).

[34] Humberto Palza, Antimicrobial Polymers with Metal Nanoparticles, Int. J. Mol. Sci., Vol.16, (2015). 